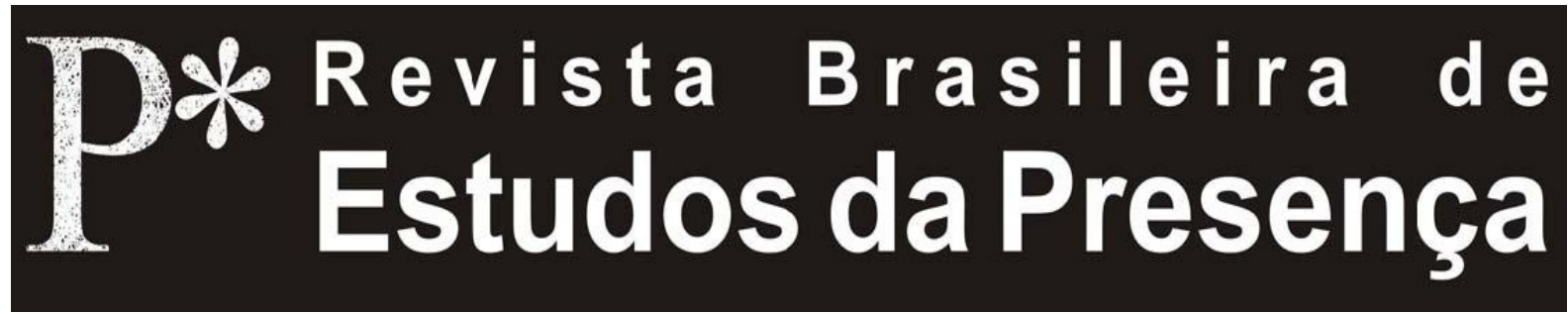

DOI - http://dx.doi.org/10.1590/2237-266025713

ISSN 2237-2660

\title{
Arthur Lessac: um ensaio sobre as energias corporais no treinamento do ator
}

\author{
Maria Regina Tocchetto de Oliveira \\ Universidade Federal da Grande Dourados - UFGD, Dourados/MS, Brasil
}

RESUMO - Arthur Lessac: um ensaio sobre as energias corporais no treinamento do ator ${ }^{1}$ - Este artigo reflete sobre os quatro estados de energia corporal desenvolvidos por Arthur Lessac: Buoyancy, Radiancy, Potency e Inter-Involvement e sobre a sua utilizaçáo no treinamento do ator. Através da análise descritiva de três exploraçóes feitas a partir da abordagem de Lessac, procura-se indicar como a aplicação das energias corporais vitaliza o jogo improvisacional, a caracterização de personagens e a ação vocal. Relaciona-se a energia do ator com a sua presença cênica.

Palavras-chave: Arthur Lessac. Energias Corporais. Presença Cênica. Improvisaçáo. Jogo do Ator.

ABSTRACT - Arthur Lessac: an essay on Body energies in actor's training - This article is a reflection on the four body energy states developed by Arthur Lessac: Buoyancy, Radiancy, Potency e Inter-Involvement and their use in the training of actors. Through a descriptive analysis of three explorations carried out according to Lessac's approach, this article indicates ways to use these energies to animate the game of improvisation, to the characterization of characters and to the vocal action. We also establish a relation between the actor's energy and his scenic presence.

Keywords: Arthur Lessac. Body Energies. Stage Presence. Improvisation. Actor's Play.

RÉSUMÉ - Arthur Lessac: un essai sur les énergies corporelles dans l'entrainement de l'acteur - Cet article propose une réflexion sur les quatre états de l'énergie corporelle développés par Arthur Lessac: Buoyancy, Radiancy, Potency et Inter-Involvement et sur leur utilisation dans l'entrainement de l'acteur. À travers une analyse descriptive de trois tentatives d'explorations élaborées à partir de l'approche de Lessac, l'auteur montre comment l'application des énergies corporelles peut revitaliser le jeu de l'improvisation, la caractérisation des personnages et l'action vocale. Il s'agit d'établir une relation entre l'énergie de l'acteur et sa présence sur scène.

Mots-clés: Arthur Lessac. Energies Corporelles. Présence Scénique. Improvisation. Jeu de l'Acteur. 
[...] a comunhão sem palavras... Nunca a sentiram, em circunstâncias semelhantes, em que algo fluiu de vocês, alguma corrente, dos seus olhos, da ponta dos seus dedos ou pelos poros? Que nome podemos dar a essas correntes invisíveis que usamos para nos comunicar uns com os outros? Algum dia este fenômeno será objeto de pesquisas científicas. Por ora, vamos chamá-los raios (Stanislavski, 1982, p. 228).

No início do século XX, o artista e pedagogo Constantin Stanislavski já se questionava sobre a importância dessas correntes invisíveis de comunicaçáo para o aperfeiçoamento da arte do ator. A nosso ver, essas correntes invisíveis de comunicação, esses raios, conforme Stanislavski mencionou, estão associados à propagação das energias corporais abordadas por Lessac na contemporaneidade. $\mathrm{O}$ Instituto Lessac, que divulga a obra de Arthur Lessac (1909-2011) e prossegue a sua pesquisa através de seus colaboradores, oferece uma abordagem concreta sobre a utilizaçáo das energias corporais para o controle e a qualidade da performance humana.

A perspectiva de Arthur Lessac nos foi apresentada através dos professores Irion Nolasco e Maria Lúcia Raymundo por ocasião de uma pesquisa universitária orientada por eles entre 1986 e 1990, no Departamento de Arte Dramática do Instituto de Artes da Universidade Federal do Rio Grande do Sul (UFRGS), intitulada A Utilização das Energias Corporais no Treinamento do Ator. Essa pesquisa extracurricular, realizada com alunos daquele Departamento, teve caráter experimental e objetivou possibilitar aos alunos/atores o treinamento e a capacidade de controle da sua energia corporal como base e canal para expressar e simbolizar suas ideias ${ }^{3}$.

O termo energia é usado com frequência no universo teatral para adjetivar e quantificar experiências, mas não é associado a um conceito definido. A noçáo de energia desenvolvida no presente artigo pode ser melhor introduzida a partir da investigação feita nos domínios da Antropologia Teatral ${ }^{4}$. De acordo com esta perspectiva, Eugenio Barba caracteriza a energia do ator como uma "[...] qualidade indescritível, intangível e incomensurável [...]" (Barba; Savarese, 1988, p. 56; tradução nossa) ${ }^{5}$, mas passível de ser estudada e utilizada, defendendo a noçáo de operacionalidade do termo energia na prática teatral.

Para o ator a energia apresenta-se na forma de um como, não na forma de um quê. Como movimentar-se. Como ficar imóvel. Como mise-en-scene, ou seja, mise-en-vision a 
sua presença física e transformá-la em presença cênica, e portanto expressão. [...] Contudo, para o ator é muito útil pensar neste como na forma de um quê, de uma substância impalpável que pode ser manobrada, modelada, cultivada, projetada no espaço, absorvida e levada a dançar no interior do corpo. Não são fantasias. São imaginaçốes eficazes (Barba, 1994, p. 77).

Eugenio Barba e seus colaboradores fizeram um cruzamento sobre procedimentos teatrais, tanto ocidentais como orientais, relacionando a energia do ator com a presença cênica.

Em toda tradição teatral existem termos de um jargão que explicam se o ator funciona como tal para o espectador ou não. Este "funcionamento" recebe muitos nomes: no Ocidente com frequência é chamado energia, vida ou simplesmente presença do ator. Nas tradiçóes teatrais orientais é definido com outros conceitos, [...] e toma o nome de prana e shakti na Índia, de koshi, ki-hai e yugen no Japáo, de chikará e taxú em Bali, de kung-fu na China (Barba; Savarese, 1988, p. 56; tradução nossa) $)^{6}$.

No contexto da mesma investigação, E. Barba ressaltou o contributo do artista e pedagogo Michael Chekhov ${ }^{7}$, que trabalhou com Stanislavski na Rússia e escreveu o manual prático Para o Ator, em 1952, nos Estados Unidos (Chekhov, 2003). Neste livro, Michael Chekhov não define o termo energia, mas o utiliza inúmeras vezes para indicar as diversas qualidades que o movimento pode ter e que enriquecem a expressividade do ator. E. Barba compara alguns exercícios propostos por Chekhov com procedimentos técnicos utilizados por Natsu Nakajima, de uma tradição teatral completamente diferente.

Parece que voltamos ao Japão, quase como se Michael Chekhov tivesse inspirado Hijikata (o fundador do Butoh, o mestre de Natzu) a estabelecer diferentes tipos de resistência através dos quais o mesmo desenho de movimentos adquire diferentes temperaturas de energia (mover-se num espaço de pedra, ou líquido, ou aéreo, para Hijikata e Natzu; modelar, flutuar, voar e irradiar, para Mikhail Tchecov). Porém, encontramo-nos perante um modo de pensar tão difundido que seria fútil buscar influências diretas (Barba, 1994, p. 113).

\section{A Especificidade de Arthur Lessac}

O Instituto Lessac, com sede nos Estados Unidos, é responsável pela pesquisa e divulgação de princípios desenvolvidos por Arthur Lessac no decorrer de sua vida profissional como artista, pedagogo 
e investigador acadêmico das disciplinas ligadas à fala, à voz e ao corpo humano. Devido ao alcance de suas descobertas, sua abordagem tem sido aplicada e servido como referência para vários campos do estudo da performance e comportamento humanos, além das artes cênicas, como os concertos musicais, o esporte, a psicologia e outros. A aprendizagem do treinamento proposto pelo Instituto é oferecida, principalmente, em forma de workshops intensivos anuais em diferentes Instituiçóes Acadêmicas dos Estados Unidos.

Um dos elementos recorrentes do treinamento Lessac ${ }^{8}$ é a exploração dos estados energéticos naturais vocais ${ }^{9}$ e corporais como recursos inesgotáveis para a qualidade de vida e a performance estética. Seu uso e controle são importantes ferramentas para o ator, que tem, justamente, como instrumentos de trabalho o seu corpo e a sua voz.

Lessac encaminha as suas pesquisas sobre o comportamento humano em direção a uma abordagem orgânica, sem a dominância de uma tendência mais física ou mais intelectual. Ao invés de diferenciar no indivíduo os aspectos exteriores relacionados com a sua materialidade física e os interiores com as suas características psicológicas e espirituais, distingue dois ambientes que constituem o palco da ação humana: o interno e o externo. $\mathrm{O}$ ambiente interno é o organismo individual de cada pessoa; o externo é tudo o que está fora disso, incluindo as outras pessoas. No ambiente interno, as ideias e os sentimentos formam-se em sinergia com a capacidade de reconhecer as sensaçóes causadas na troca com o ambiente externo (Lessac, 1978). Lessac chama Harmonic overtone sensory system à consciência perceptiva do ambiente interno pessoal.

O "harmonic overtone sensory system" é alimentado e sinergizado por todos os sistemas vivenciais do corpo: os sistemas de memória; os processos imagéticos e associativos; os sistemas nervosos; os sistemas vocal e muscular... todo o cérebro! (Lessac, 1978, p. 29; tradução nossa) ${ }^{10}$.

O Harmonic overtone sensory system pode ser entendido como uma coordenação sincronizada das sensaçóes produzidas, através dos cinco sentidos, da percepção destas sensações, de acordo com os demais sistemas de experiência interna, e das reaçóes geradas visando à comunicação com o outro e com o ambiente externo.

Segundo a abordagem de Lessac, as energias corporais e vocais podem ser experimentadas no ambiente interno individual e fazem 
parte dos sistemas de linguagem utilizados pelo indivíduo para se comunicar com o ambiente externo.

Estou interessado nas linguagens do corpo que funcionam como portadoras de inteligência pessoal, perceptividade pessoal, imaginação pessoal e cultura pessoal; linguagens sensoriais dentro de cada um de nós que são tanto nativas como estrangeiras, voluntárias e não voluntárias (Lessac, 1978, p. 30; tradução nossa).

O treinamento promovido pelo Instituto Lessac é um processo experiencial "[...] onde as qualidades de energia são fisicamente sentidas, percebidas e então sintonizadas e usadas na expressão criativa" (Lessac, 1997, p. 3; tradução nossa) ${ }^{11}$. O autor prefere considerar os exercícios propostos no treino como exploraçóes, procedimentos ou práticas. Nesse sentido, valoriza o envolvimento integral do indivíduo durante as atividades de exploração vivenciadas.

O foco de nossa atenção no presente artigo recai sobre os quatro estados de energia corporal desenvolvidos pelo treino Lessac: Buoyancy, Radiancy, Potency e Inter-Involvement e sobre a maneira como a exploração desses quatro estados energéticos pode enriquecer a prática do ator.

A caracterizaçáo feita por Lessac desses quatro estados energéticos corporais obedece, a nosso ver, a duas funçóes principais: a reguladora, ao mesmo tempo relaxante e vitalizante, que estimula o corpo a reagir com frescor às necessidades internas e às investidas do ambiente externo, deixando-o com o tônus equilibrado, sem crispaçóes nem flacidez muscular; e a funçáo expressiva, caracterizada pelas mudanças rítmicas corporais, pelas diferentes relaçóes do corpo com o espaço e pelas variadas sensaçóes corporais que os estados energéticos proporcionam.

Abaixo, segue a especificação dos quatro estados de energia ${ }^{12}$ corporal.

\section{Buoyancy}

Buoyancy é o estado energético em que é possível experimentar a ausência de peso e de esforço físico, como se o corpo estivesse carregado de oxigênio e fosse mais leve que o ar. É como um relaxamento ativo, diferente daquele relaxamento em que se sente o corpo pesado. O estado psicofísico relacionado com buoyancy caracteriza-se geralmente pela calma, serenidade, estabilidade e leveza. 
Uma das tendências ao experimentar o estado de buoyancy é a de manter o ritmo em câmera lenta, mas pode ser desenvolvido em alta velocidade. No entanto, a experiência de leveza em slowmotion, que suaviza a respiraçáo e o movimento, ajuda a perceber toda a potencialidade da vida e da movimentação internas que há na imobilidade externa.

Em condiçóes normais, sem o advento de expectativas traumáticas com a água, o contato direto com esta energia pode ser vivenciado, também, quando se está dentro de uma massa de água como o mar, um lago, uma piscina ou mesmo uma banheira. Neste campo de suporte, através de uma respiração equilibrada, pode-se naturalmente encontrar a sensação de flutuação em certas partes do corpo ou no corpo todo. A sensação de flutuação, a leveza e a fluidez experimentadas dentro da água são eventos naturais ou familiares, isto é, experiências involuntárias ou semivoluntárias que se transformam em instruçóes orgânicas quando, voluntariamente, deseja-se reproduzir aquelas sensaçôes através da memória sensorial e sem o suporte aquático da experiência pioneira.

Pode-se retomar a sensaçáo de buoyancy através de uma imagem, de um ritmo específico, de uma postura de equilíbrio, de uma forma de respirar, da lembrança de um cheiro e até da própria ideia desse estado energético. Segundo o treinamento Lessac, é possível manejar o uso da energia de buoyancy náo só de forma voluntária, mas também como comportamento que emerge de forma instintiva para dar suporte, consistência, leveza e dinamismo à performance.

Além das qualidades salutares e estéticas que o uso da energia de buoyancy proporciona ao movimento corporal, é importante lembrar o seu potencial no campo expressivo. É considerada um dos dialetos da linguagem corporal, pois tem o seu modo próprio de funcionamento, a sua tendência rítmica e espacial, a sua relaçáo entre tônus e equilíbrio e, também, uma sintonia própria com certas zonas do comportamento humano. Características como leveza, fluidez, suavidade e expansividade podem ser encontradas explorando essa energia. No entanto, náo se pode fixar um rótulo de correspondência, por exemplo, com as zonas de tranquilidade, estabilidade, sensualidade, etc. Nesta área, não é interessante criar padróes de comportamento que conduziriam necessariamente à criação de estereótipos.

De acordo com os pesquisadores Irion Nolasco e Maria Lúcia Raymundo, o que interessa é a possibilidade de fazermos perguntas 
e utilizarmos esses estados energéticos corporais como estimuladores de uma busca expressiva ${ }^{13}$. Pode-se perguntar, por exemplo, que estilo teatral pode ser incitado com o jogo dos atores construído a partir do ritmo, da plasticidade e das dinâmicas de equilíbrio dos diferentes estados energéticos? Que tipo de personagem apresenta tais características energéticas?

\section{Radiancy}

Radiancy é o outro dialeto ou idioma da linguagem corporal. Caracteriza-se pela excitaçáo vibradora do corpo, que pode ser ou mais sofisticada e sutil, como um contínuo tremor leve e suave, ou apresentar-se na forma elétrica da personificação da agilidade e destreza corporal, ou ainda apresentar-se como um estado de alerta e antecipação.

Lessac disponibiliza vários exemplos de eventos recheados de radiancy. Devido às características de surpresa, excitação, divertimento e espontaneidade, o estado energético de radiancy lembra muito a atitude da criança quando brinca com energia inesgotável, com liberdade e equilibrando, naturalmente, o relaxamento com repentinas sobrecargas energéticas.

$\mathrm{O}$ precoce gatinho com seus movimentos imprevistos e seus elétricos e fascinantes olhos - empertigando-se, brincando, saltando, girando, rolando e de repente parando - é todo energia de radiancy! O comportamento astuto, sempre alerta de Charlie Chaplin ou Laurel e Hardy no antigo cinema mudo é radiancy a funcionar. $\mathrm{O}$ veado em repentino alerta ao primeiro farejar de intrusos - o sapateado mais-leve-que-o-ar do imortal Bill Robinson - o vigia noturno sempre desprendido com o objetivo de estar sempre em guarda - o corredor mesmo antes do sinal da partida - os músicos de orquestra em prontidáo à espera do sinal feito com a batuta do maestro para o primeiro compasso musical - todas estas imagens são obtidas com a energia de radiancy (Lessac, 1978, p. 48; tradução nossa) ${ }^{14}$.

Como a liberação da energia de radiancy começa geralmente pelos olhos na criança pequena, uma das exploraçôes previstas no treinamento estimula a excitação e a curiosidade no olhar, disparando-o em várias direçôes e deixando que essa atividade ligeira e divertida vá estimulando as áreas mais próximas, como a face, as orelhas, a boca e a cabeça, para depois, como uma corrente de eletricidade, fluir até os dedos, mãos, braços e seguir preenchendo o corpo todo. Dessa forma, a vibração corporal pode tornar-se ora sutil, como o estado 
mais contido de alerta do caçador antes de disparar em direção à sua presa, ora explosiva, capaz de instalar os padróes da dança caribenha, com as suas sacudidelas ágeis de quadris e ombros.

O vibrato corporal mais sutil pode servir como um elemento importante na conquista do peso vivo em oposição ao peso morto. Como um energizador, o estado energético de radiancy vitaliza a atividade muscular, eliminando a sensação de passividade e de desmotivação.

\section{Potency}

Potency é o estado energético que configura a sensação de potência muscular. $\mathrm{O}$ evento familiar dessa energia é o espreguiçamento muscular acompanhado do bocejo sonoro, que vitaliza o corpo, alongando e relaxando a musculatura "[...] com uma sensação de impetuosa e profunda intensidade [...]” (Lessac, 1978, p. 52; tradução nossa) ${ }^{15}$.

Para conscientizar esse estado energético natural e torná-lo instrução orgânica, o treinamento Lessac sugere a comparação da sensação de potência em oposição à experiência esgotante da força bruta. A diferença está na respiração. Quando se está no auge da inspiração do bocejo, a força real aumenta, pois o corpo recebe grande quantidade de oxigênio, causando a sensação de alta voltagem muscular. A experiência tende a distribuir-se, abrangendo uma maior área de fibras musculares envolvidas, evitando o stress físico causado pela suspensão da respiração e pelo esforço localizado, que geralmente acontecem quando a força bruta é acionada. Assim, utilizando potency, a pessoa não só se sente mais forte, como está realmente mais forte em comparação com o esforço feito pelo caminho do máximo stress.

De forma a evitar o excesso de tensão e crispação muscular aliados à ideia de força, o treinamento Lessac contempla a experimentação da energia de potency com a energia de buoyancy em algumas exploraçóes, como, por exemplo, no evento familiar do espreguiçamento. Depois de espreguiçar todo o corpo, depois de se atingir o auge da expansão e da sensação de potência se desvanecer, o resíduo é a sensação flutuante da energia de buoyancy.

As sensaçóes aliadas a este estado são de extremo vigor, ilimitada potência, poder e autodeterminaçáo causadas pela capacidade de máximo estiramento e extensão corporal sem esforço. Com a energia de potency, o corpo se amplia e se estende de forma estável e intensa. 


\section{Inter-Involvement}

O quarto estado energético desenvolvido pelo treinamento Lessac é o de Inter-Involvement e diz respeito à comunicação orgânica do ambiente interno individual com o ambiente externo.

Mesmo a mais pura técnica é uma técnica pobre quando o envolvimento pessoal interno está faltando. Mas estarmos envolvidos com a percepção de nossos próprios estados energéticos corporais não é a mesma coisa que a sensação de inter-involvement.

Pegue, por exemplo, os princípios do nosso trabalho, Sabedoria Corporal. Sim, nós podemos aprender a apreciar as sensaçóes e percepçóes de buoyancy, radiancy e potency e a reconhecê-las como parte de uma rede de resposta para nós mesmos. Mas sem a cobertura do inter-involvement, nós nunca iremos produzir um rendimento emocionalmente carregado de nosso organismo interno para o ambiente externo. Mesmo no nosso próprio trabalho, haverá técnicos da Sabedoria Corporal e artistas da Sabedoria Corporal. Os primeiros manipulam proficientemente o processo sensorial mas em apenas um quarto do potencial, os artistas orquestrarão os diferentes elementos do harmonic overtone sensory system e explorarão o instrumento psicofísico em seu inteiro potencial. A energia de inter-involvement é uma condição necessária, não apenas suficiente, para o ótimo treinamento da Sabedoria Corporal (Lessac, 1978, p. 55; tradução e grifos nossos) ${ }^{16}$.

$\mathrm{O}$ estado de inter-involvement fundamenta-se na necessidade que o indivíduo tem de relacionar-se, impulsionando-o a sintetizar todos os seus sistemas de experiência interna em direção aos seus objetivos, sem estar autoconsciente do uso que faz de seus estados energéticos ou dos outros elementos estéticos e expressivos que otimizam a performance. De certa forma, o corpo não se carrega propriamente de uma energia como as outras três, mas de um cruzamento híbrido desses estados efetuado pelo sistema emocional.

$\mathrm{O}$ estado de inter-involvement relaciona-se com a atitude de exploração, curiosidade e prazer, bem como com a irradiaçáo da presença cênica, pois integra harmoniosamente todas as potencialidades individuais do ator no jogo de ação e reação com o momento presente.

Com o objetivo de exemplificar a utilização na prática do ator dos quatro estados de energia corporal identificados por Lessac, a presente investigação descreverá e analisará três exploraçôes vivenciadas pela autora como aluna, atriz e pesquisadora. 
As duas exploraçôes mencionadas a seguir descrevem improvisaçôes feitas durante o Lessac Summer Intensive Workshop 2006. O curso orientado por Deborah Kinghorn e Kattleen Dunn decorreu na Universidade DePaw, em Greencastle, Indiana, entre os dias 18 de Junho a 16 de Julho.

\section{Descrição 1 - situaçáo proposta para improvisação}

Depois de familiarizar os alunos com as noçôes básicas do treinamento, as professoras instigaram o grupo à seguinte improvisação: imagine que uma criança muito pequena que você ama está brincando no parapeito de uma janela aberta do $4^{\circ}$ andar. Quando você percebe o perigo e deseja arrancá-la de lá imediatamente, instintivamente sabe que não pode assustar a criança com gritos e atitudes explosivas, que poderiam causar a sua queda, mas, também, que não pode perder um único segundo até o momento de segurá-la. Deve atraí-la suavemente para si (uso de buoyancy), enquanto galvaniza o seu corpo com agilidade total para chegar até a criança o mais rápido possível (uso de radiancy) e segurá-la com a força máxima para vencer as suas resistências, mas com delicadeza, sem rigidez para não machucá-la e, em um golpe só, afastá-la totalmente do perigo (uso de potency). Assim, tem-se um exemplo da maneira como os quatro estados energéticos se inter-relacionam e equilibram um no outro, tendo o inter-involvement a tarefa de sintetizá-los. Quando se está verdadeira e integralmente envolvido numa atividade, esse estado equivale a "[...] uma força magnética diametralmente oposta ao esforço físico" (Lessac, 1978, p. 56; tradução nossa $)^{17}$. Seria possível comparar o estado de inter-involvement ao envolvimento do ator com as circunstâncias ${ }^{18}$ que definem a situação da personagem e influenciam ou justificam o seu comportamento, ou com a partilha do jogo criado pelo ator em relação a seus colegas e à plateia. Esse estado também pode se identificar com a energia presente na contracenação dos atores, ou com o sentido que impulsiona as açóes do ator no palco, independentemente do projeto teatral em que estiver inserido.

\section{Descriçáo 2 - jogo com as energias, descoberta de personagem e improvisaçáo}

O treinamento Lessac privilegia a característica lúdica da performance, ressaltando a atitude de curiosidade, motivação e disponibilidade do indivíduo para evoluir a caminho do imprevisto na 
sua troca com os parceiros. Esta foi a perspectiva de uma exploração desenvolvida no workshop, em que o grupo era estimulado a criar diferentes personagens, a partir do jogo com as energias.

No início da exploraçáo, os participantes eram orientados a deixarem-se levar pelas características específicas e pelos impulsos momentâneos que cada um dos três estados energéticos suscitava. A cada troca de energia anunciada, assumiam uma maneira de se comportar, de olhar, de andar, de falar e de estabelecer contato. Ao circularem pela sala, imbuídos pelas suas personagens, entravam em contato uns com os outros, apresentando-se e deixando-se influenciar por este encontro, sem perder a matriz energética original. Depois de experimentarem três personagens diferentes, originados do jogo alternado com as energias de buoyancy, radiancy e potency, optavam por uma delas, escolhiam um parceiro e começavam a improvisar, em duplas. A situação sugerida era a de uma entrevista de emprego. Sem combinar previamente, os participantes permitiam que o jogo indicasse quem faria o papel de empregador e o de entrevistado. A seguir, cada dupla apresentava o desenvolvimento da situaçáo para a plateia, formada pelos colegas e pelas professoras. Como não existe um padráo que caracterize a personificação de radiancy, buoyancy, ou potency, as personagens criadas eram todas diferentes e, como uma situação de entrevista para emprego sugere, a princípio, um contraste de perspectiva entre empregador e potencial empregado, as atitudes dos jogadores sempre divergiam.

O desenvolvimento dessa proposta nos permitiu perceber que existem dois momentos distintos no procedimento com as energias corporais: o primeiro consiste na exploração em laboratório, onde procuramos isolar o seu efeito e preencher o corpo todo com seu estado; o segundo consubstancia-se na sua utilização na performance, em que uma outra série de condiçóes canaliza e determina a sua adequada aplicação. É nesse âmbito que aparece o estado de inter-involvement, ou a capacidade de manejar intuitivamente uma série de estímulos de origens variadas, focalizando a atenção de forma desejada. Aquele jogo teatral com as personagens instigava cada participante a equilibrar toda sorte de informaçôes, sensaçôes, impressóes, sentimentos, impulsos e imagens produzidos, na troca constante com o parceiro, com a plateia e com as regras da improvisaçáo. A nossa consciência era estimulada a tornar-se dinâmica, integrando os processos de sentir, perceber, identificar e responder. Se em situação de laboratório 
conseguíamos circunscrever a maior parte da manifestação comportamental da personagem dentro das variaçóes de um único registro energético, no momento em que a púnhamos para relacionar-se, o fluxo energético era completamente alterado. Mantínhamos a essência energética como origem, mas variávamos as qualidades das nossas ações dentro de um espectro maior de energias corporais. Foi então que se tornaram claras, para mim, as qualidades expressivas do trabalho energético com as personagens. Existe uma função que auxilia a caracterização da essência das personagens e outra que caracteriza a variação expressiva de cada momento do jogo.

Qualquer situaçáo na vida tem o seu desenvolvimento. Desde que acordamos até o final do nosso dia, passamos por uma infinidade de pequenos ou grandes acontecimentos acompanhados por uma constante alteraçáa do nosso estado de espírito. Isso inclui uma também constante variação energética, para nos adequarmos às necessidades expressivas do momento. Inspirar-se neste dinamismo para representar a vida no jogo teatral implica dispor de uma capacidade de transformaçáo energética, corporal, mental e emocional. Isso foi possível perceber na exploração ora analisada. Todos os participantes, em seus pares, pareciam variar as energias, para além do planejamento inicial, porque a situaçáo da entrevista assim o exigia. Por exemplo, açóes executadas como: chegar ao encontro, apresentar-se, esperar, suspeitar, esconder, expor, avançar, recuar, conquistar, desistir, vencer ou perder foram momentos que se sucederam com a evolução das situaçóes, de maneiras sempre diferentes, exigindo uma flexibilização dos intérpretes, impossível de levar a bom termo se não fosse de forma intuitiva, encaminhada por uma sabedoria natural.

$\mathrm{Na}$ análise investigativa da presente descrição fica clara a função que a energia de inter-involvement teve no desempenho dos integrantes do grupo, entre atores e não atores. Era o estado energético de inter-involvement que sinergizava as energias trabalhadas de forma orgânica e imprevista. Não se viam as características de buoyancy, radiancy e potency dominarem a performance de forma completa. Observavam-se momentos cheios de cada uma delas, mas era possível reparar noutros, em que estavam mescladas a ponto de não se conseguir identificar qual era o principal estado energético a liderar a ação. Essa exploração nos conduz à seguinte reflexão: a energia é um procedimento psicofísico que flui, que se propaga, e, sobretudo, se transforma. Trocamos energia com o meio ambiente, com as ou- 
tras pessoas a todo o momento, apenas não nos damos conta deste trânsito com a mesma velocidade em que ele acontece. Para o ator, isso tem grande importância, pois o jogo teatral náo é só uma troca intelectual de ideias e objetivos, é também uma influência direta de estados, sentimentos e sensaçóes manifestados energeticamente em sintonia com a atitude geral e demais aspectos da linguagem gestual. O corpo fala o tempo inteiro. Comunica até a sua ausência, quando atuamos de forma desconcentrada e irradia a sua presença mesmo quando desejamos instalar a neutralidade expressiva. Nesse âmbito, comunicamos em cena, com maior ou menor intensidade e controle. É por isso que a utilização das energias corporais na prática do ator deve ser compreendida como uma atitude a ser incorporada, e náo como uma técnica a que o ator recorre eventualmente. A eficácia da abordagem com as energias corporais depende de um contínuo processo de treinamento, baseado numa autoaprendizagem, efetuada no cotidiano e em situação de representação.

\section{Descrição 3 - criação de uma personagem dramática, integra- ção entre corpo e voz, e improvisação}

A presente descrição refere-se a uma exploração feita em 1988, no Departamento de Arte Dramática da UFRGS, por ocasião da pesquisa $A$ utilização das energias corporais no treinamento do ator, orientada por Irion Nolasco e Maria Lúcia Raymundo, e da qual a autora participava como aluna/atriz.

$\mathrm{O}$ procedimento em questáo foi proposto de forma similar para todos os alunos/atores que integravam a pesquisa, mas será narrado aqui com base na experiência da autora, por dela ter maior consciência e memória. A exploraçâo era baseada na escolha e memorização de um solilóquio extraído de um texto clássico do teatro e tinha como objetivo estimular os alunos/atores a encontrarem novas e instigantes maneiras de articular o texto expressivamente. Escolhi, para esse fim, as três bruxas de Macbeth, de Shakespeare, articulando as suas falas em torno de uma só personagem. O foco principal da exploração era descobrir como integrar as diferentes energias corporais com a açáo vocal, para que toda a variação expressiva conseguida com o treinamento corporal influenciasse a fala, enriquecendo-a de nuances e flexibilizando-a para o jogo cênico. A experiência tinha início com a incorporação de uma das três energias no corpo de forma extravagante, ou seja, sem improvisar açóes propriamente ditas, 
mas deixando o corpo impregnar-se da referência registrada na memória, a partir de exploraçôes anteriores com a energia em questáo. Enquanto eu dizia o texto, os orientadores indicavam as mudanças energéticas corporais que era preciso assumir. Além disso, eu deveria liberar a emissão vocal da maneira habitual de falar, evitando seguir as regras gramaticais de pontuaçáo e sintaxe, e detendo a fala apenas por necessidade de respiração. Desta forma, eu era constantemente surpreendida e desafiada a evitar os padróes pessoais de expressão vocal. Minha principal tarefa era ficar disponível para integrar a fala com as transformaçóes rítmicas e energéticas originadas pelo desenvolvimento dos impulsos corporais, e, ao mesmo tempo, conscientizar a influência da ação vocal nas sensaçóes corporais. Como os estados energéticos corporais estão ligados a todos os aspectos do nosso ser, a produçáo de sensações, sentimentos e significados aflorava incessantemente, junto com a ininterrupta movimentação e com a emissão vocal. Instintivamente, eu associava imagens e ideias surgidas no momento com registros da memória corporal e emocional e selecionava os caminhos a serem aprofundados durante a improvisação. Com essa exploração, eu pude descobrir, para além do maquiavelismo e do grotesco que caracterizam o estereótipo de uma bruxa, características como a liberdade, a submissão, a potência, o prazer, o senso de humor e as imensas contradiçóes afetivas ligadas à pureza e à maldição.

A leveza, a sensualidade, a entrega ou a autocomplacência que podem estar contidas dentro do alcance expressivo da energia de buoyancy permitiram, ao serem experimentadas, fortalecer, por oposição, as ações obsessivas estimuladas pela fúria, que galvaniza o corpo com a sua energia de potency para a destruição, ou para a determinação pragmática da crueldade. A energia de radiancy revelou a extrema agilidade e sentido de alerta contidos nos jogos, brincadeiras e na execução das tarefas realizadas pela personagem. $\mathrm{O}$ uso das três energias, integradas pelo estado de inter-involvement, embalaram os trabalhos cerimoniais dessa bruxa, destacando o lirismo e o componente estético da personagem. Estético ${ }^{19}$, neste caso, no sentido indicado por Lessac, mais ligado à harmonia das sensaçóes e consequente expressividade do intérprete do que relacionado à natureza do belo. Como aluna e investigadora, compreendi que o uso de diferentes energias corporais auxilia a descoberta de uma personagem de forma orgânica, isto é, sem precisar aderir aos estereótipos disponíveis. 
Como o foco do exercício trabalhado era a descoberta da expressividade vocal da personagem, os orientadores encaminharam o próximo passo da exploração, no sentido de transformar as conquistas recém-obtidas num discurso e numa gestualidade mais contidos.

Lessac estabelece níveis diferentes de discurso de acordo com as necessidades de comunicação. Esta experiência, relativa às primeiras fases de aplicação dos elementos do treinamento Lessac, é por ele qualificada como extravagante. Mais contido e direcionado é o discurso formal e mais ligado à conversaçáo normal é o informal. Conforme o autor, os três tipos de discurso podem ser usados na representação teatral, dependendo da configuração do espaço de apresentação, com suas condições acústicas, e dos objetivos estéticos e expressivos do projeto.

Tudo o que havia sido experimentado através do jogo com as energias corporais e o seu correlato vocal, de forma difusa e descontrolada, deveria, agora, ser aproveitado de um jeito mais contido, e de acordo com a situaçáo dramática proposta. Foi possível perceber, com essa nova improvisação, que os momentos de exploraçáo anterior que haviam sido estabelecidos como significativos apareceram nesse outro formato. Além disso, as energias executadas originalmente através de uma movimentação ampla e extravagante permaneciam intactas na contenção externa, encontrando-se ainda mais intensas, já que foram represadas.

Se transpusermos os tipos de discurso sugeridos acima e suas combinaçóes para a ótica dos estilos teatrais, no que se refere à gestualidade, podemos perceber que a expressão das energias corporais não depende do formato do gesto, nem da sua amplitude, podendo ser irradiadas mesmo por um corpo parado externamente ou através de sua ação vocal.

O outro ensinamento que resultou dessa experiência foi o desenvolvimento da confiança nos sistemas internos e intuitivos, já que, ao serem estimulados, resultaram de forma eficiente na produção de respostas criativas. $\mathrm{O}$ treinamento Lessac sugere esta atitude de constante aprendizagem, baseada na exploração das potencialidades inatas para fortificar a percepção que o indivíduo tem de si, enriquecendo sua performance no equilíbrio com o ambiente externo. 


\section{Consideraçóes Finais}

A descrição e análise das exploraçóes destacadas, com o objetivo de ressaltar a importância das energias corporais no treinamento do ator, levam-me à seguinte reflexão: compreender na prática que as energias corporais se transformam é usufruir da liberdade expressiva exigida para a constante readaptaçáo e formulaçáo de respostas adequadas aos estímulos externos ou às necessidades internas. Dessa forma, podemos reconhecer no treinamento Lessac, como também acontece com alguns métodos de preparaçáo do ator, um ponto de contato para influenciar os sistemas de comportamento nãovoluntário, cuja ativação e harmonia com a porção voluntária do artista é fundamental à performance. Além disso, utilizar diferentes qualidades energéticas para colorir de forma simbólica as açóes desenvolvidas durante a representaçáo teatral é encontrar uma maneira de transpor para a realidade artística a multifacetada experiência vivida, sem competir com ela. Embora a abordagem de Lessac náo seja uma metodologia de preparação para a arte do ator, acreditamos que as suas premissas antropológicas, suas exploraçóes e procedimentos contemplam alguns pontos-chave da prática teatral e contribuem, como vislumbravam os pesquisadores Irion Nolasco e Maria Lúcia Raymundo, para renovar e vitalizar a performance do ator.

No início deste artigo, citamos a reflexão de Stanislavski sobre os raios ou as correntes invisiveis que parecem ir de uma pessoa à outra em atos de comunicação. E, ainda, a sua conjetura de que esta seria uma área de investigação científica do futuro. $\mathrm{O}$ presente ensaio procurou mostrar evidências que indicam uma evolução desta investigação no campo da pedagogia das artes cênicas. A Antropologia Teatral, através da sua perspectiva transdisciplinar e transcultural, divulgou registros de experiências por um lado únicas e, por outro, semelhantes no que concerne ao treinamento do ator sobre a sua energia corporal. A apresentação do ponto de vista de Arthur Lessac exemplifica uma estratégia que permite experimentar estas "correntes" de que fala Stanislavski. A intensidade destas experiências e desta estratégia indicam, a nosso ver, um caminho para o treinamento da presença cênica do ator. 


\section{Notas}

${ }^{1}$ Este artigo, inédito em língua portuguesa, é uma versão revista e ampliada do artigo intitulado The Body Energies in the Actor's Performance publicado em Collective Writings on the Lessac voice and Body Works. OLIVEIRA, Maria Regina Tocchetto de. The Body Energies in the Actor's Performance. In: Collective Writings on the Lessac voice and Body Works. TURNER, Sean; MUNRO, Marth; MUNRO, Allan; CAMPBELL, Kathleen (Org.). Coral Springs: Llumina Press, 2009. P. 411-427.

${ }^{2}$ Irion Nolasco entrou em contato com a abordagem de A. Lessac através da sua participação em um workshop realizado nos anos 1980, nos EUA.

${ }^{3}$ A demonstração prática dos resultados da pesquisa $A$ utilização das energias corporais no treinamento do ator foi apresentada no dia 6 de novembro de 1989 na sala Qorpo-Santo, em Porto Alegre, por ocasião da premiação do grupo no Concurso Jovem Pesquisador do I Saláo de Iniciaçáo Científica promovido pela PROPESP da UFRGS. Nessa apresentaçáo, o orientador Irion Noloasco refletiu sobre a contribuição dos artistas e pedagogos norteadores do projeto; entre eles figurava Arthur Lessac. Ver Oliveira, 2008.

${ }^{4}$ Projeto de investigação realizado por Eugênio Barba e pela equipe de colaboradores da ISTA, International School of Theatre Antropology, e que estuda o comportamento biológico e cultural do homem em situação de representação (Barba; Savarese, 1988).

5 “[...] una cualidad indescriptible, intangible e inconmensurable [...]".

6 "En toda tradición teatral existen términos de una jerga que explican si el actor funciona como tal para el espectador o no. Este 'funcionamiento' recibe muchos nombres: en Occidente a menudo es llamado energía, vida o simplemente presencia del actor. En las tradiciones teatrales orientales es definido con otros conceptos, como veremos y toma el nombre de prana y shakti en la India, de koshi, ki-hai y yugen en Japón, de chikará y taxù en Bali, de kung-fu en China".

${ }^{7}$ Optamos por utilizar a grafia do nome de Michael Chekhov como aparece na obra consultada por nós. (Chekhov, 2003). E mantivemos a grafia escolhida por E. Barba (1994) na citação que faz do autor Mikhail Tchekhov.

${ }^{8}$ No site do Instituto Lessac, encontra-se como "Lessac Training" ou "Lessac Kinesensic Training". Disponível em: <http://www.lessacinstitute.com>. Acesso em: 15 jun. 2012.

${ }^{9} \mathrm{O}$ treinamento Lessac contempla a expressividade da fala através da integraçáo da voz com as energias corporais. E desenvolve, além disso, um trabalho com a energias ligadas mais especificamente à vida vocal, que são the tonal energy, the structural energy e the consonant energy e que náo estão sendo contempladas neste artigo. Sobre o tema, ver Lessac (1997).

10 "The 'harmonic overtone sensory system' is fed and synergized by all the experiencing systems of the body: the memory systems; the imaging and associative processes; the nervous systems; the vocal and muscular systems... the whole brain!".

11 " $[. .$.$] where energy qualities are physically felt and perceived, then tuned and used for$ creative expression". 
${ }^{12}$ A partir daqui, iremos utilizar os termos e expressões: estados de energia corporal, energias corporais e energias como semelhantes, de acordo com o seu uso em Lessac (1978).

${ }^{13}$ Esta iniciativa foi uma das perspectivas da pesquisa, já anteriormente citada, $A$ utilização das energias corporais no treinamento do ator, quando Nolasco e Raymundo procuravam levar mais adiante a proposta energética de Lessac.

14 "The precocious kitten with its unpredictable moves and its fascinating, electric eyes - prancing, playing, leaping, turning, rolling, sudden stopping - is all radiancy energy! The artful, ever-alert body behaviour of Charlie Chaplin or Laurel and Hardy in the old silent movies is radiancy at work! The deer on sudden guard at the first scent of intruders - the great "lighter-than-air" tap dancing of immortal Bill Robinson - the night-watch always loose in order to be always on guard - the track-runner just before the Go signal - the symphony musicians on sudden "nerve-tingly" anticipation of their maestro's first downbeat - all of these images obtain to radiancy energy".

15 “[...] with a sense of fierce and deep intensity [...]".

16 "Even the purest technique is poor technique when inner personal involvement is lacking. But to self-involved with the perception of your own body energy states is not quite the same thing as the sensation of inter-involvement! Take, for example, the principles of our own work, Body Wisdom. Yes, we can learn to feel the sensations and perceptions of buoyancy, radiancy, and potency and recognize these as part of a network of self-to-self response. But without the overlay of inter-involvement, we can never generate emotionallycharged output from our internal organism to the outer environment. Even in our own work, there will be technicians of Body Wisdom and artists of Body Wisdom. Where the former manipulates the feeling process proficiently but with only one-quarter yield, the artist will orchestrate the different elements of the harmonic overtone sensory system and exploit the psycho-physical instrument to its fullest potential. Inter-Involvement energy is thus a necessary, not merely sufficient, condition for optimal training to Body Wisdom”.

17 “[...] a magnetic force diametrically opposed to sheer brawn".

${ }^{18}$ O termo "circunstâncias" faz referência ao termo "dadas circunstâncias" utilizado por Constantin Stanislavski para descrever o conjunto de condiçóes que o ator deve levar em conta para a criação de uma personagem (Stanislavski, 1982, p. 77-78).

19 Termo traduzido de "esthetic", que tem origem na palavra esthesis, relacionada ao estudo das sensaçóes, como Lessac prefere utilizar, evitando a noçáo advinda de aesthetic, relacionada com a natureza do belo (Lessac, 1997).

\section{Referências}

BARBA, Eugenio. A Canoa de Papel: tratado de antropologia teatral. Sáo Paulo: Editora Hucitec, 1994.

BARBA, Eugenio; SAVARESE, Nicola. Anatomia del Actor: dicionário de antropología teatral. México: Colección Escenologia, 1988. 
CHEKHOV, Michael. Para o Ator. São Paulo: Martins Fontes, 2003.

LESSAC, Arthur. Body Wisdom: the use and training of the human body. New York:

Lessac Research, 1978.

LESSAC, Arthur. The Use and Training of the Human Voice. New York: McGraw-Hill, 1997.

LESSAC Institute. Disponível em: <http://www.lessacinstitute.com>. Acesso em 15 jun. 2012.

OLIVEIRA, Maria Regina Tocchetto de. As Energias Corporais no Trabalho do Ator. 2008. 103 f. Dissertação (Mestrado em Estudos de Teatro) - Faculdade de Letras, Universidade de Lisboa, Lisboa, 2008. [Disponível na Biblioteca Carlos Barbosa do Instituto de Artes da UFRGS].

OLIVEIRA, Maria Regina Tocchetto de. The Body Energies in the Actor's Performance. In: TURNER, Sean; MUNRO, Marth; MUNRO, Allan; CAMPBELL, Kathleen (Org.).

Collective Writings on the Lessac voice and Body Works. Coral Springs: Llumina Press, 2009. P. 411-427.

STANISLAVSKI, Constantin. A Preparação do Ator [1936]. Rio de Janeiro: Civilização Brasileira, 1982.

STANISLAVSKI, Constantin. A Construçáo da Personagem. Rio de Janeiro: Civilização Brasileira, 1986.

STANISLAVSKI, Constantin. Minha Vida na Arte. Rio de Janeiro: Civilização Brasileira, 1989.

Maria Regina Tocchetto de Oliveira é atriz, diretora e professora de Teatro. É mestre em Estudos Teatrais pela Universidade de Lisboa (2008) e bacharel em Interpretação Teatral pela Universidade Federal do Rio Grande do Sul (1991). Docente no Curso de Artes Cênicas, da Faculdade de Comunicação, Artes e Letras da Universidade Federal da Grande Dourados/MS, tem experiência na área de Artes, com ênfase em Atuação. O foco de sua Pesquisa são as Energias Corporais no Trabalho do Ator. E-mail: tocchettogina@hotmail.com

Recebido em 01 de fevereiro de 2012 Aprovado em 05 de novembro de 2012 